\title{
Basic and advanced imaging of a case of Balò's concentric sclerosis
}

\author{
Paolo Ripellino, ${ }^{1,2}$ Alessandro Stecco, ${ }^{3}$ Maurizio A Leone, ${ }^{2}$ Roberto Cantello ${ }^{2}$
}

${ }^{1}$ Department of Neurology, University of Turin, Torino, Italy ${ }^{2}$ Department of Neurology, University of Eastern Piedmont, AOU Maggiore della Carità, Novara, Italy

${ }^{3}$ Department of Radiology, University of Eastern Piedmont AOU Maggiore della Carità, Novara, Italy
A

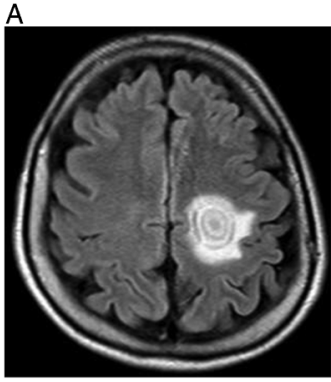

B

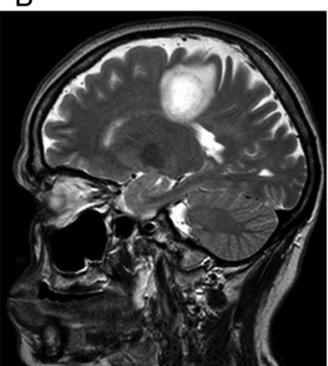

Figure 1 At diagnosis. (A) Axial fluid attenuated inversion recovery sequence and (B) sagittal T2-sequence evidence the typical concentric ring lesion in the white matter.
Conventional MRI scans (figure 1A,B) were typical for Balò's sclerosis. ${ }^{1}$

The patient rejected a brain biopsy. In order to better define the lesion, we therefore performed advanced radiological techniques such as diffusion, spectroscopy and perfusion.

In the diffusion sequences (figure 2A) a concentric ring of unrestricted diffusion appeared clearly distinguishable. $^{2}$

The spectroscopic image (figure 2B) of the lesion documented increased choline peak and decreased $\mathrm{N}$-acetyl aspartate peak, but normal peaks in the normal appearing white matter near the lesion. ${ }^{1}$ different regions of interest (figure 2D), suggested a decreasing gradient of perfusion from the centre to the periphery of the lesion, supporting the hypothesis that the centre of the ring corresponds anatomically to a deep venous vessel. ${ }^{3}$ Authors are not aware of previous report of perfusion studies in Balò's sclerosis.

Cerebrospinal fluid analysis detected oligoclonal bands, without anti-aquaporin-4 antibodies.
The perfusion analysis (figure $2 \mathrm{C}$ ), based on four
A

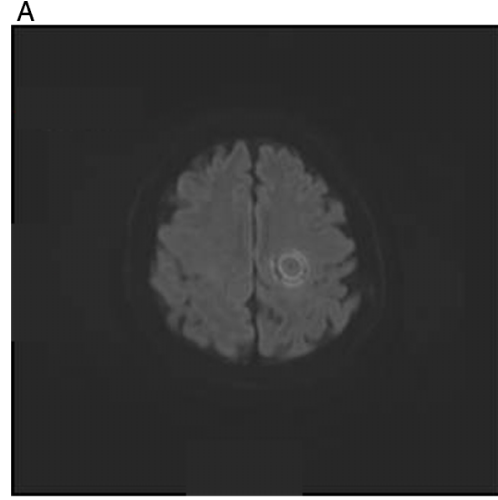

B

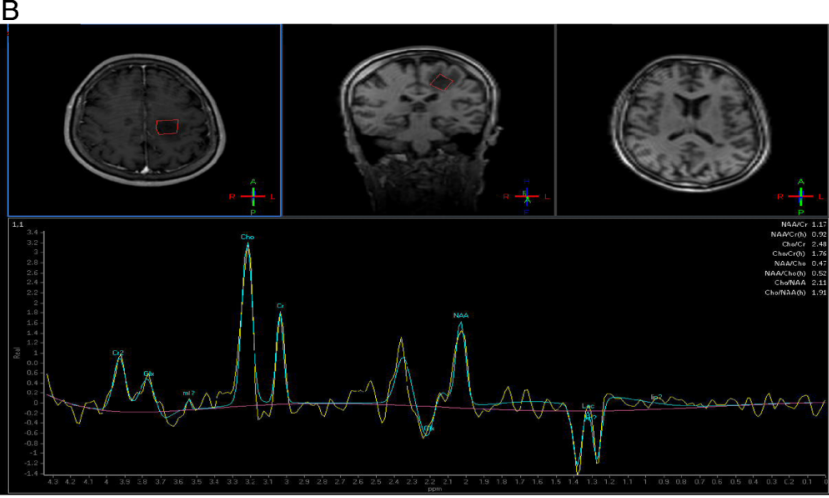

C

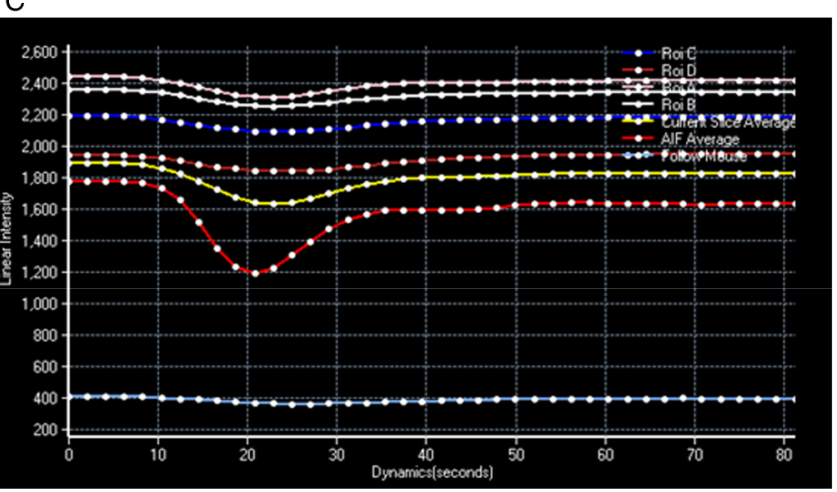

D

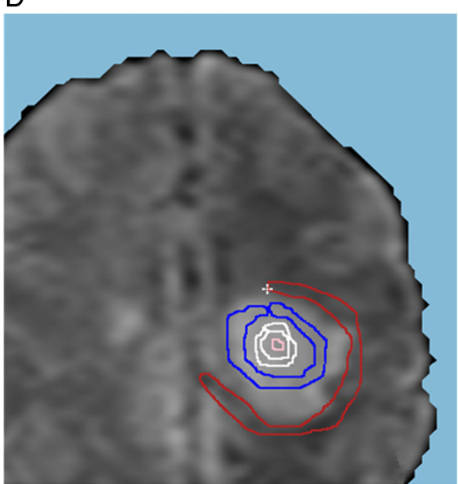

To cite: Ripellino $P$ Stecco A, Leone MA, et al. BMJ Case Reports Published online: [please include Day Month Year] doi:10.1136/ bcr-2012-008413
Figure 2 At diagnosis. (A) Diffusion shows a restricted peak depicting the classical ring of demyelination and remyelination. (B) Spectroscopy shows a high ratio Cho/N-Acetylaspartate, double pick of lactate-lipids. (C) Perfusion MRI analysis, based on four regions of interest depicted in $D(A$, pink, $B$, white, $C$, blue, $D$, red) suggests that the central layers of the ring are more perfused compared to the peripheral ones. 


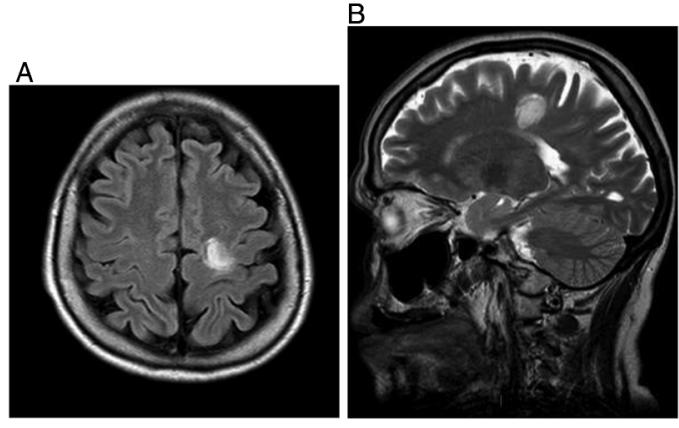

Figure 3 At 8 months follow-up (after treatment). (A) Axial fluid attenuated inversion recovery sequence and (B) sagittal T2-sequence evidence the reduction in the lesion volume compared to figure 1.

High-dose intravenous methylprednisolone was started ( $1 \mathrm{~g} /$ day for 10 days) and followed by oral prednisone ( $1 \mathrm{mg} / \mathrm{kg} /$ day for 2 months, then slowly tapered in 2 months) with concomitant lamivudine as antiviral prophylaxis. The right paresis fully recovered after 2 weeks and has not relapsed after 11 months.

The 8 months follow-up MRI showed a reduction in the lesion volume and absence of new demyelinating lesions (figure $3 \mathrm{~A}, \mathrm{~B}$ ).

\section{Learning points}

- Balò's concentric sclerosis is a rare demyelinating disease presenting with a concentric ring in the white matter. The clinical and radiological features can mimic other diseases such as primary central nervous system lymphoma, low-grade glioma or stroke.

- A brain biopsy should be obtained whenever possible. However, nowadays advanced neuroimaging studies (spectroscopy, MRI diffusion and perfusion) seem to be a reliable tool for the diagnosis.

- Balò's sclerosis could respond very well to high-dose steroids alone or in combination with other immunosuppressive treatments (eg, plasma exchange).

\section{Competing interests None.}

Patient consent Obtained.

Provenance and peer review Not commissioned; externally peer reviewed.

\section{REFERENCES}

1 Karaarslan E, Altintas A, Senol U, et al. Balò's concentric sclerosis: clinical and radiologic features of five cases. AJNR Am J Neuroradiol 2001;22:1362-7.

2 Kavanagh EC, Heran MK, Fenton DM, et al. Diffusion-weighted imaging findings in Balo concentric sclerosis. Br J Radiol 2006;79:e28-31.

3 Khonsari RH, Calvez V. The origins of concentric demyelination: self-organization in the human brain. PLOS One 2007;2:e150.

Copyright 2013 BMJ Publishing Group. All rights reserved. For permission to reuse any of this content visit http://group.bmj.com/group/rights-licensing/permissions.

BMJ Case Report Fellows may re-use this article for personal use and teaching without any further permission.

Become a Fellow of BMJ Case Reports today and you can:

- Submit as many cases as you like

- Enjoy fast sympathetic peer review and rapid publication of accepted articles

- Access all the published articles

- Re-use any of the published material for personal use and teaching without further permission

For information on Institutional Fellowships contact consortiasales@bmjgroup.com

Visit casereports.bmj.com for more articles like this and to become a Fellow 